\title{
AVALIAÇÃO DA QUALIDADE DA ÁGUA DE POÇOS RASOS NO MUNICÍPIO DE COLINAS - RS
}

\author{
Caroline Saling ${ }^{I}$, Amanda Gräff ${ }^{1}$, Eniz Conceição Oliveira ${ }^{2 *}$, Wolmir José Böckel ${ }^{3}$ \\ ${ }^{1}$ Centro de Ciências Exatas e Tecnológicas, Centro Universitário UNIVATES, 95900.000, Lajeado, Brasil. \\ ${ }^{2}$ Mestrado em Ensino de Ciências Exatas, Centro Universitário UNIVATES, 95900.000, Lajeado, Brasil. \\ ${ }^{3}$ Centro de Ciências Exatas e Tecnológicas, Centro Universitário UNIVATES, 95900.000, Lajeado, Brasil.
}

*E-mail: eniz@univates.br

Recebido em: 28/07/2016.

Aceito em: 13/03/2017.

\section{RESUMO}

A água é de fundamental importância para a biodiversidade, sendo considerada um recurso natural indispensável ao homem. Nos últimos tempos, a sociedade polui e degrada este recurso de tal forma que já não se pode consumi-lo em seu estado natural. Porém, com a ascensão da tecnologia, é possível o monitoramento, tratamento e preservação de recursos hídricos. Neste estudo foram realizadas análises físico-químicas e microbiológicas de amostras de água de doze poços rasos no município de Colinas - RS. Foram realizadas análises de $\mathrm{pH}$, condutividade, turbidez, cor, cloreto, fluoreto, bromato, brometo, nitrato, nitrito, sulfato, número mais provável de coliformes totais e número mais provável de Escherichia coli. Os resultados foram comparados com os padrões de potabilidade preestabelecidos pela Portaria No 2914/2011 do Ministério da Saúde. Verificou-se que todas as amostras apresentaram contaminação microbiológica e que, para os parâmetros físico-químicos analisados, somente cinco de um total de doze amostras estão em conformidade com a legislação brasileira. A situação torna-se potencialmente grave quando esta água contaminada é destinada a consumo humano.

Palavras-chave: Água. Poço raso. Qualidade Físico-química. Análise Microbiológica.

\section{Introdução}

A água existente sobre a terra (aproximadamente 1,37 milhões de $\mathrm{km}^{3}$ ) é, aparentemente, fácil de ser encontrada para o consumo. Entretanto, do volume total de água, $97,2 \%$ é água salgada; $2,1 \%$ é neve ou gelo; apenas $0,6 \%$ é água doce; o restante é vapor atmosférico [1].

A água utilizada para o consumo humano é a potável, cujos parâmetros microbiológicos, físicos, químicos e radioativos devem atender ao padrão de potabilidade e não oferecer riscos à saúde humana [2]. A palavra potável significa água que se pode beber, ou seja, que pode ser ingerida ou utilizada no preparo de alimentos e na higiene pessoal [3]. A água não pode conter elementos que sejam prejudiciais à saúde, isto é, não pode conter substâncias tóxicas, nem organismos patogênicos. A determinação da qualidade da água tem como objetivo, atestar sua conformidade com os padrões estabelecidos como ideais [4]. As atividades de controle da qualidade visam saber se a água mantém a qualidade desejada para o consumo [4].

Fertilizantes, esgotos domésticos e excrementos de animais, sem tratamento, escorrem para os aquíferos, isto é, podem infiltrar-se no solo e atingir o lençol freático ou cair diretamente nas águas superficiais e subterrâneas. Esses são os maiores problemas de contaminação dos recursos hídricos em regiões rurais [5]. A situação torna-se potencialmente grave quando esta água contaminada é destinada ao consumo humano. A desinformação da população aliada à subestimação ou à omissão dos órgãos fiscalizadores ambientais estão na origem do problema.

Alguns estudos que analisaram águas naturais em algumas regiões do Brasil obtiveram dados importantes sobre a qualidade das fontes naturais. Num estudo da qualidade das águas naturais do município de Alegrete - RS, cinco amostras de trinta e cinco analisadas apresentaram valores fora dos limites estabelecidos pelo Ministério da Saúde para os parâmetros de $\mathrm{pH}$, cloretos, alcalinidade e cálcio. Segundo o estudo, a situação problemática estaria relacionada à ação antrópica ou a diferenças geológicas [4]. Noutro trabalho [6], foram analisadas quatro fontes naturais nos municípios de Estrela - RS e Cruzeiro do Sul - RS. Constatou-se que, para as análises de $\mathrm{pH}$, condutividade, sólidos suspensos, turbidez, oxigênio dissolvido, carbono orgânico, carbono total, carbono inorgânico, nitrogênio, dureza média e temperatura, todas as fontes ficaram com os parâmetros dentro dos padrões mínimos de qualidade para consumo humano estabelecidos pela Resolução CONAMA 357/2005 [7]. Já na região central e sul do Brasil, verificou-se que todas as fontes analisadas apresentaram resultados com parâmetros entre as classes 1 e 2, incluídas nos padrões mínimos de qualidade estabelecidos pelo CONAMA [7] para as análises de $\mathrm{pH}$, condutividade, turbidez, dureza média e temperatura [8]. 
O presente estudo teve como objetivo analisar os parâmetros físico-químicos e microbiológicos, tais como $\mathrm{pH}$, condutividade, turbidez, cor, cloreto, fluoreto, bromato, brometo, nitrato, nitrito, sulfato, número mais provável (NMP) de coliformes totais e NMP de E. coli em amostras de água de doze poços rasos, coletadas no município de Colinas-RS e avaliar se os níveis estão de acordo com os padrões de potabilidade estabelecidos pela legislação [2].

\section{Metodologia}

A área de estudo foi o município de Colinas (Figura 1), localizada no Vale do Taquari, na Região Central do estado do Rio Grande do Sul, com latitude de $29,3^{\circ}$ ao sul e longitude de $51,5^{\circ}$ a oeste. Sua área total é $58,4 \mathrm{~km}^{2}$. A população total é 2.420 habitantes, dos quais 1.315 são da zona rural e 1.105, da zona urbana [9].

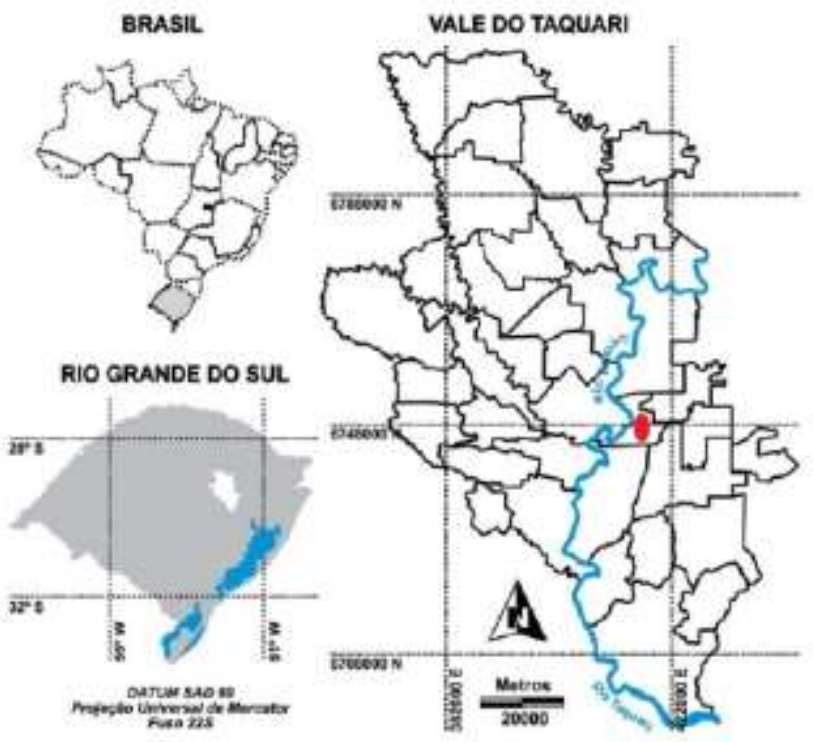

Figura 1. Localização do Município de Colinas (em vermelho) no Vale do Taquari, Rio Grande do Sul - Brasil [10] Adaptado.

Foram coletadas doze amostras de água de poços distribuídos pelo município de Colinas-RS, identificadas numericamente conforme a Figura 2.

Para as análises físico-químicas, as amostras foram coletadas em recipientes com capacidade de $1000 \mathrm{~mL}$, limpos e previamente identificados. Em frascos com capacidade para $100 \mathrm{~mL}$, contendo uma pastilha de tiossulfato de sódio, coletouse a amostra para as análises microbiológicas. A coleta para ambas as análises foi realizada conforme a metodologia do Standard Methods for The Examination of Water and Wastewater [11].
No momento da coleta, foi realizada a medição da temperatura com um termômetro com coluna em vidro, (Incoterm), bem como, a medição do $\mathrm{pH}$ da água com um pHmetro portátil, (AZ).

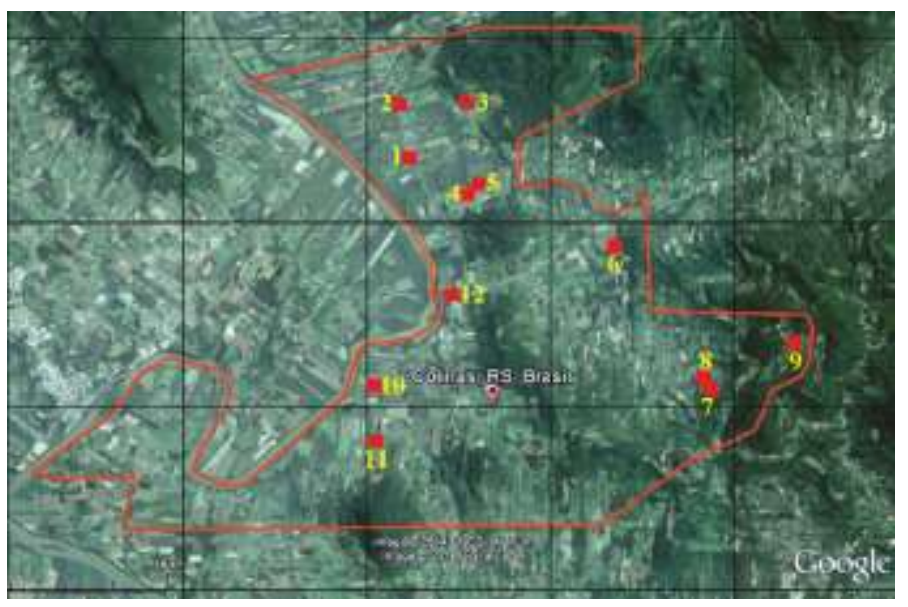

Figura 2. Região geográfica do Município de Colinas-RS, onde foram coletadas amostras de água nos pontos enumerados de 1 a 12 [12] Adaptado.

Também foi medida a profundidade dos poços com uma trena métrica e identificadas as coordenadas geográficas de cada poço com o auxílio de um GPS Garmin, modelo Vista HCX - Etrex. As amostras foram acondicionadas em recipiente térmico para conservação em baixa temperatura e proteção contra a luz até chegarem ao laboratório, onde foram mantidas em geladeira entre $2^{\circ} \mathrm{C}$ a $8{ }^{\circ} \mathrm{C}$ até serem analisadas.

As análises físico-químicas como $\mathrm{pH}$, condutividade, turbidez e cor foram realizadas em até 24 horas após o horário da coleta. As análises de ânions foram realizadas por leitura direta num cromatógrafo iônico com detector de condutividade, coluna Metrosep A Supp 5 - 150/4.0, operando com fluxo de $0,700 \mathrm{~mL} \min ^{-1}$, pressão $9,47 \mathrm{MPa}$ e temperatura $30,0{ }^{\circ} \mathrm{C}$. Todas as análises foram feitas em triplicata. As metodologias conforme Standard Methods for The Examination of Water and Wastewater [11] e os modelos dos equipamentos utilizados estão descritos na Tabela 1.

Tabela 1 - Metodologias e equipamentos utilizados para análises físicoquímicas conforme Standard Methods for The Examination of Water and Wastewater [11].

\begin{tabular}{|c|c|c|}
\hline Análise & $\begin{array}{c}\text { Método } \\
{[12]}\end{array}$ & $\begin{array}{c}\text { Equipamento } \\
\text { (origem de fabricação) }\end{array}$ \\
\hline $\mathrm{pH}$ & $4500 \mathrm{~B}$ & Digimed DM-22 (Brasil) \\
\hline Condutividade & $2510 \mathrm{~B}$ & Digimed DM-32 (Brasil) \\
\hline Turbidez & $2130 \mathrm{~B}$ & Digimed DM-TU (Brasil) \\
\hline Colorimetria & $2120 \mathrm{~B}$ & Digimed DM-COR (Brasil) \\
\hline Ânions & $2510 \mathrm{~B}$ & $\begin{array}{c}\text { Metrohm } 881 \text { Compact IC Pro } \\
\text { (Suíca) }\end{array}$ \\
\hline
\end{tabular}


As análises microbiológicas foram realizadas em até 24 horas após o horário da coleta. A metodologia utilizada na análise do número mais provável de coliformes totais e no NMP de E. coli foi o método 9221B do Standard Methods for The Examination of Water and Wastewater [11].

\section{Resultados e discussões}

As Tabelas 2 e 3 apresentam os resultados da coleta e das análises das doze amostras de água. O resultado apresentado é a média das triplicatas.

Tabela 2 - Resultados obtidos no momento da coleta das doze amostras.

\begin{tabular}{cccc}
\hline AMOSTRA & Temperatura $\left({ }^{\circ} \mathrm{C}\right)$ & $\mathrm{pH}$ & Profundidade $(\mathrm{m})$ \\
\hline 1 & 20 & 7,2 & 2,4 \\
2 & 22 & 7,1 & 2,0 \\
3 & 20 & 7,6 & 2,1 \\
4 & 22 & 6,9 & 1,0 \\
5 & 22 & 6,7 & 1,0 \\
6 & 21 & 7,2 & 1,3 \\
7 & 20 & 6,7 & 1,5 \\
8 & 20 & 7,2 & 1,6 \\
9 & 18 & 6,7 & 1,0 \\
10 & 21 & 7,0 & 4,2 \\
11 & 22 & 7,4 & 1,6 \\
12 & 22 & 7,2 & 2,4 \\
\hline
\end{tabular}

Todas as amostras apresentaram contaminação microbiológica, tanto de coliformes totais quanto de E. coli, sendo que o NMP em ambas as análises foi maior que 8,0 $\mathrm{NMP} / 100 \mathrm{~mL}$. Esses resultados podem ser explicados considerando as más condições de conservação dos poços. Os poços rasos, situados acima da camada rochosa, são mais suscetíveis às contaminações, ao contrário dos aquíferos artesianos, que estão confinados por camadas relativamente impermeáveis, que protegem as águas de possíveis contaminações [13].
No momento da coleta das amostras, a água dos poços $1,2,8$ e 10 estava exposta ao meio ambiente, sem nenhuma proteção contra sujidades, animais, plantas ou precipitações naturais de água. Os poços $3,4,5,6,7,9,11$ e 12, que tinham uma tampa protetora para a água, estavam com a proteção danificada e coberta por vegetação em decomposição (Figura 3). Além disso, todos os poços localizam-se em áreas próximas a residências ou estábulos de animais. Entre as principais fontes de contaminação das águas pode-se citar os esgotos, que, nas cidades e nas regiões agrícolas, são lançados no solo, poluindo rios, lagos e lençol freático [14].

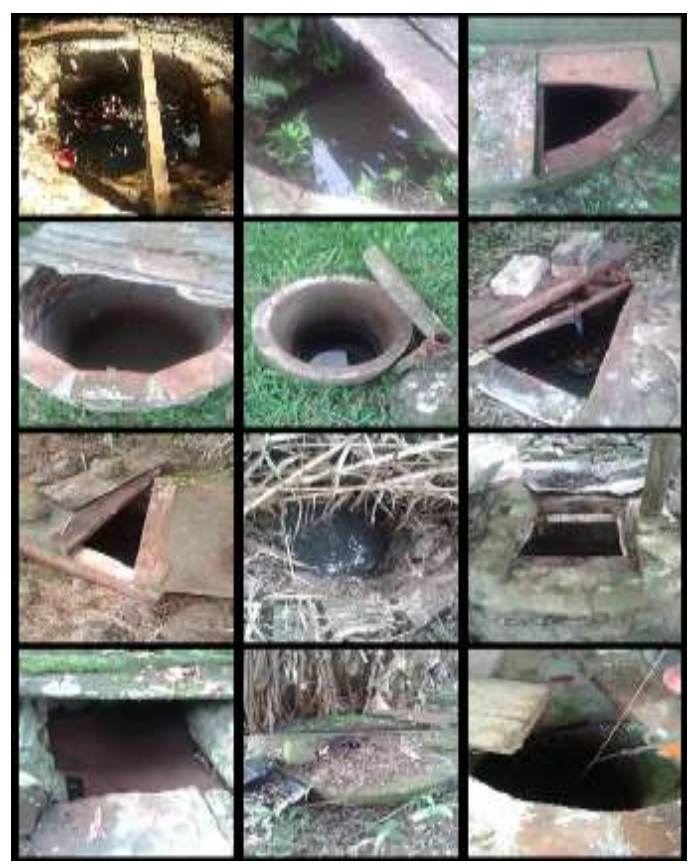

Figura 3. Imagens dos poços rasos localizados em Colinas-RS, identificados numericamente de 1 a 12 .

Tabela 3 - Resultados das análises físico-químicas das amostras de água do município de Colinas - RS.

\begin{tabular}{ccccccccccc}
\hline Poço & $\mathrm{pH}$ & $\begin{array}{c}\text { Condutividade } \\
\left(\mu \mathrm{S} \mathrm{cm}^{-1}\right)\end{array}$ & $\begin{array}{c}\text { Turbidez } \\
(\mathrm{NTU})\end{array}$ & Colorimetria $(\mathrm{uH})$ & $\begin{array}{c}\text { Fluoreto } \\
\left(\mathrm{x} 10^{-2} \mathrm{mg} \mathrm{L}^{-1}\right)\end{array}$ & $\begin{array}{c}\text { Cloreto } \\
\left(\mathrm{mg} \mathrm{L}^{-1}\right)\end{array}$ & $\begin{array}{c}\text { Nitrito } \\
\left(\mathrm{x} \mathrm{10} \mathrm{mg} \mathrm{L}^{-1}\right)\end{array}$ & $\begin{array}{c}\text { Brometo } \\
\left(\mathrm{mg} \mathrm{L}^{-1}\right)\end{array}$ & $\begin{array}{c}\text { Nitrato } \\
\left(\mathrm{mg} \mathrm{L}^{-1}\right)\end{array}$ & $\begin{array}{c}\text { Sulfato } \\
\left(\mathrm{mg} \mathrm{L}^{-1}\right)\end{array}$ \\
\hline 1 & $6,99 \pm 0,26$ & $159,05 \pm 0,21$ & $17,34 \pm 0,01$ & $60,03 \pm 0,38$ & $6,20 \pm 0,00$ & $3,71 \pm 0,00$ & $0,3 \pm 0,0$ & $\mathrm{ND}^{*}$ & $3,23 \pm 0,00$ & $8,17 \pm 0,03$ \\
2 & $6,78 \pm 0,21$ & $251,50 \pm 4,77$ & $4,17 \pm 0,11$ & $14,17 \pm 0,25$ & $4,70 \pm 0,00$ & $6,35 \pm 0,00$ & $\mathrm{ND}^{*}$ & $0,13 \pm 0,00$ & $11,11 \pm 0,00$ & $8,35 \pm 0,10$ \\
3 & $6,84 \pm 0,07$ & $134,33 \pm 0,22$ & $27,87 \pm 0,12$ & $90,70 \pm 0,20$ & $6,80 \pm 0,01$ & $0,99 \pm 0,01$ & $0,9 \pm 0,0$ & $\mathrm{ND}^{*}$ & $0,33 \pm 0,00$ & $1,32 \pm 0,03$ \\
4 & $6,80 \pm 0,01$ & $349,50 \pm 1,05$ & $0,43 \pm 0,01$ & $3,03 \pm 0,31$ & $11,60 \pm 0,00$ & $9,36 \pm 0,01$ & $\mathrm{ND}^{*}$ & $0,15 \pm 0,00$ & $5,36 \pm 0,00$ & $7,10 \pm 0,10$ \\
5 & $6,88 \pm 0,11$ & $371,53 \pm 3,68$ & $0,33 \pm 0,01$ & $4,23 \pm 0,25$ & $11,80 \pm 0,00$ & $6,66 \pm 0,01$ & $\mathrm{ND}^{*}$ & $0,20 \pm 0,00$ & $2,22 \pm 0,00$ & $6,22 \pm 0,09$ \\
6 & $6,99 \pm 0,05$ & $187,61 \pm 0,99$ & $15,67 \pm 0,01$ & $55,37 \pm 0,59$ & $10,00 \pm 0,00$ & $3,17 \pm 0,00$ & $\mathrm{ND}^{*}$ & $0,10 \pm 0,07$ & $0,98 \pm 0,00$ & $1,52 \pm 0,00$ \\
7 & $6,46 \pm 0,16$ & $80,43 \pm 0,93$ & $11,35 \pm 0,04$ & $42,40 \pm 0,52$ & $2,60 \pm 0,00$ & $2,25 \pm 0,00$ & $\mathrm{ND}^{*}$ & $\mathrm{ND}^{*}$ & $1,12 \pm 0,00$ & $2,10 \pm 0,00$ \\
8 & $7,22 \pm 0,04$ & $814,60 \pm 3,25$ & $17,31 \pm 0,02$ & $95,97 \pm 0,45$ & $8,20 \pm 0,01$ & $58,83 \pm 0,05$ & $1,0 \pm 0,0$ & $0,14 \pm 0,00$ & $0,65 \pm 0,00$ & $4,74 \pm 0,06$ \\
9 & $6,50 \pm 0,11$ & $61,00 \pm 5,35$ & $1,32 \pm 0,03$ & $4,83 \pm 0,32$ & $2,40 \pm 0,00$ & $1,66 \pm 0,01$ & $\mathrm{ND}^{*}$ & $\mathrm{ND}^{*}$ & $0,46 \pm 0,00$ & $1,66 \pm 0,01$ \\
10 & $6,29 \pm 0,04$ & $202,37 \pm 0,45$ & $2,99 \pm 0,07$ & $14,30 \pm 0,26$ & $4,50 \pm 0,00$ & $9,47 \pm 0,01$ & $\mathrm{ND}^{*}$ & $0,11 \pm 0,00$ & $1,00 \pm 0,00$ & $9,54 \pm 0,00$ \\
11 & $6,88 \pm 0,06$ & $228,33 \pm 1,79$ & $6,53 \pm 0,07$ & $19,67 \pm 0,51$ & $21,70 \pm 0,01$ & $4,10 \pm 0,08$ & $\mathrm{ND}^{*}$ & $\mathrm{ND}^{*}$ & $3,19 \pm 0,00$ & $2,48 \pm 0,07$ \\
12 & $6,77 \pm 0,05$ & $380,43 \pm 8,89$ & $0,25 \pm 0,05$ & $2,00 \pm 0,72$ & $6,60 \pm 0,00$ & $13,00 \pm 0,00$ & $\mathrm{ND}^{*}$ & $3,44 \pm 0,00$ & $3,44 \pm 0,00$ & $11,86 \pm 0,02$ \\
\hline
\end{tabular}


Conforme relatos dos proprietários dos poços, a água dos poços 1, 4, 6, 7, 11 e 12 é utilizada para uso em irrigação e dessedentação de animais; não é utilizada para consumo humano. Os poços 2, 3 e 9 estavam desativados, isto é, não estavam em uso. No momento das coletas, a água dos poços 5, 8 e 10 estava sendo utilizada para consumo humano, além de ser usada na irrigação e para consumo dos animais. Apesar de a água não ser destinada ao consumo humano, o uso para a irrigação e para a dessedentação de animais também pode levar a implicações negativas, tais como: a entrada de micro-organismos patógenos e contaminantes químicos na cadeia alimentar humana, via hortaliças irrigadas com água contaminada, e na cadeia alimentar de animais, via consumo da água contaminada [15].

A presença de coliformes termotolerantes na água indica a presença de esgotos, o que, por sua vez, significa a possibilidade da presença de patogênicos, dada a provável existência de pessoas doentes ou portadoras em meio à população que deu origem àqueles esgotos [3]. A E. coli é a bactéria mais representativa dentro do grupo dos coliformes termotolerantes; portanto, sua presença é indicativa de coliformes fecais, pois esta bactéria é habitante do trato intestinal de humanos e animais de sangue quente [16].

Os resultados obtidos foram analisados de acordo com a Portaria No 2914 de 12 de dezembro de 2011 [2], que dispõe sobre os procedimentos de controle e de vigilância da qualidade da água para consumo humano e sobre seu padrão de potabilidade, estabelecendo os padrões individuais de cada substância em cada classe quanto à qualidade da água. Por essa Portaria, determinam-se os parâmetros de pH, entre 6,0 e 9,5; turbidez até $5 \mathrm{NTU}$; nível de cor até $15 \mathrm{uH}$; cloreto até $250 \mathrm{mg} \mathrm{L}$ 1 ; nitrato até $10 \mathrm{mg} \mathrm{L}^{-1}$; fluoreto até $1,5 \mathrm{mg} \mathrm{L}^{-1}$; sulfato até 250 $\mathrm{mg} \mathrm{L}^{-1}$; e bromato até $0,025 \mathrm{mg} \mathrm{L}^{-1}$. Conforme os resultados obtidos, todas as amostras estão de acordo com os padrões estabelecidos pela referida portaria [2] para as análises de fluoreto, cloreto, sulfato e bromato (Figura 4).

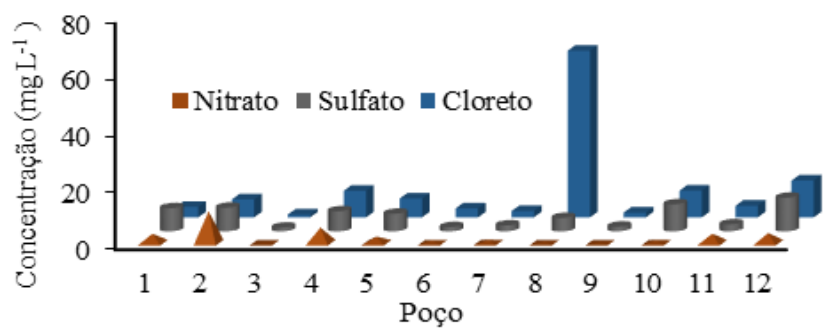

Figura 4. Resultados das análises de nitrato, sulfato e cloreto.
A amostra 2 apresentou $11,11 \mathrm{mg} \mathrm{L}^{-1} \pm 0,00 \mathrm{mg} \mathrm{L}^{-1} \mathrm{de}$ nitrato; portanto, não está de acordo com a legislação [2] em relação a este parâmetro. As outras amostras estão de acordo com a legislação em relação ao critério de nitratos. O nitrato é o produto final da estabilização aeróbia do nitrogênio orgânico. Níveis elevados de nitratos indicam possibilidades de contaminação por disposição inadequada de dejetos humanos, industriais ou de indústrias alimentícias, além do uso de fertilizantes nitrogenados na agricultura. Nesse caso, o alto valor de nitrato na amostra 2 pode ser atribuído à disposição inadequada de dejetos humanos, pois observou-se que sua localização estava próxima a uma residência, longe da zona industrial de Colinas. A contaminação por nitrato na água de beber pode trazer graves consequências à saúde, visto que, no organismo humano, o nitrato se converte em nitrito que, por sua vez, combina-se com a hemoglobina para formar a metaemoglobina, que impede o transporte de oxigênio no sangue [14].

A condutividade elétrica é determinada pela presença de substâncias dissolvidas que se dissociam em íons e conduzem corrente elétrica. Os resultados de condutividade variaram de $61,00 \mu \mathrm{S} \mathrm{cm}^{-1} \pm 5,35 \mu \mathrm{S} \mathrm{cm}-1$ a $814,60 \mu \mathrm{S} \mathrm{cm}^{-1} \pm 3,25 \mu \mathrm{S} \mathrm{cm}^{-1}$ (Figura 5). A amostra 8 apresentou o maior resultado de condutividade, $814,60 \mu \mathrm{S} \mathrm{cm}^{-1} \pm 3,25 \mu \mathrm{S} \mathrm{cm}^{-1}$, possivelmente em função da maior concentração de cloretos, $58,83 \mathrm{mg} \mathrm{L}^{-1} \pm 0,05$ $\mathrm{mg} \mathrm{L}^{-1}$.

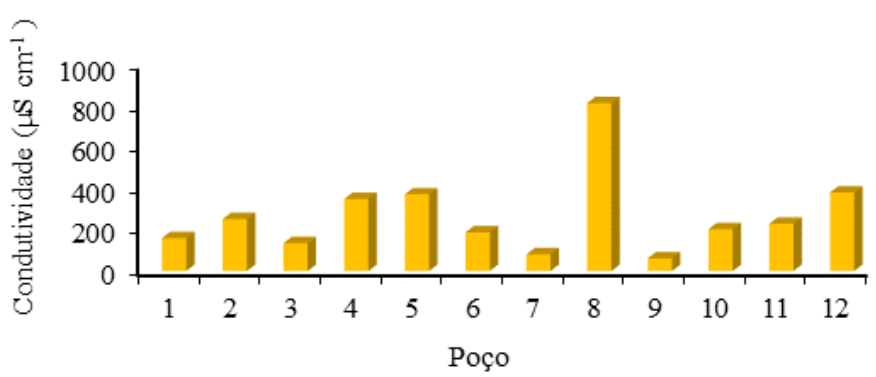

Figura 5. Resultados das análises de condutividade nos 12 poços.

A determinação de cloretos pode estar relacionada à poluição, sendo, por isso, um indicador de contaminação de águas, a qual pode ocorrer por causa do escoamento de esgotos domésticos ou de aterros sanitários e lixões. A determinação de cloretos é realizada para verificar a dissolução de sais e o lançamento de esgotos domésticos e industriais em um corpo hídrico [17,18]. A alta concentração (maiores de $1000 \mathrm{mg} . \mathrm{L}^{-1}$ ) de cloretos em água pode afetar o crescimento das plantas e também pode acarretar danos à saúde pública, causando, entre outras 
doenças, hipercloremia, doenças renais e desidratação na população [19].

Os valores obtidos na análise de turbidez variaram de $0,25 \mathrm{NTU} \pm 0,05 \mathrm{NTU}$ a 17,34 NTU $\pm 0,01$ NTU (Figura 6) e por colorimetria, de 2,00 uH $\pm 0,72 \mathrm{uH}$ a 95,97 $\mathrm{uH} \pm 0,45 \mathrm{uH}$ (Figura 7). As amostras 1, 3, 6, 7, 8 e 11 não estão de acordo com a legislação quanto ao parâmetro de turbidez (valores maiores que 5 NTU), nem segundo o parâmetro de cor, pois apresentaram resultados maiores que $15 \mathrm{uH}$. Estes poços estão localizados em áreas rurais do município de Colinas, em contato direto com pastagens e a vegetação natural do local. A presença de pastagens e de cobertura de campo contribui de forma mais acentuada para o aumento da turbidez do que se houvesse predomínio de florestas [20]. A turbidez é atribuída, principalmente, às partículas sólidas em suspensão. A cor, esteticamente indesejada, pode ter origem mineral ou vegetal, causada por substâncias metálicas, matérias húmicas, algas, plantas aquáticas e protozoários [21]. As demais amostras (2, 4, 5, 9, 10 e 12) estão em conformidade com a legislação [2] em relação aos parâmetros de turbidez e cor.

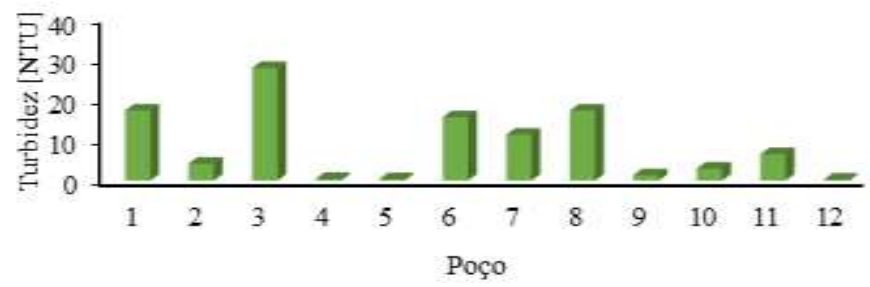

Figura 6. Comparação dos resultados da análise de turbidez nos doze poços analisados.

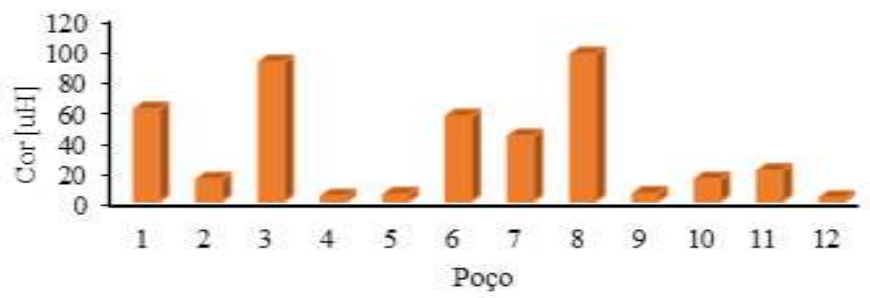

Figura 7. Comparação dos resultados da análise de cor nos doze poços analisados.

Além disso, todas as amostras estão em conformidade com a legislação de acordo com o pH, que se refere à concentração de íons de hidrogênio numa solução.

Houve grande variabilidade de resultados entre as amostras analisadas. Um estudo aponta que esta característica de variabilidade de resultados é justificada pela distribuição espacial dos poços, com incidência em diferentes formações geológicas, o que produz amplo intervalo de variação de valores para uma mesma variável [22].

\section{Conclusões}

O presente estudo evidenciou que todas as amostras apresentaram contaminação microbiológica. Em relação aos parâmetros físico-químicos analisados, somente as amostras 4, 5, 9, 10 e 11 estão de acordo com os valores estabelecidos na Portaria $\mathrm{N}^{\mathrm{o}}$ 2914. Nas análises de $\mathrm{pH}$, fluoreto, cloreto, sulfato e bromato, todas as amostras se classificaram de acordo com os valores estabelecidos por esta legislação.

Verificaram-se sinais de contaminação microbiológica e alterações nos parâmetros físico-químicos na água de poços do município de Colinas. É importante monitorar estes poços para garantir a potabilidade da água e o seu consumo em condições adequadas. A desinfecção da água destes poços utilizando o processo da cloração, por exemplo, pode ser eficiente para a remoção dos contaminantes microbiológicos, o que já melhora a qualidade da água dos poços.

Desta forma, pode-se concluir que o futuro do uso da água de poços em Colinas deve ser controlado por análises físicoquímicas e microbiológicas com maior frequência. Além disso, deve haver programas de informação e de conscientização à população pelos órgãos fiscalizadores ambientais e de saúde pública. A água de poços rasos é identificada como um recurso natural limitado, que deve ser monitorado, a fim de evitar maiores riscos à saúde da população, bem como, garantir sua preservação.

\section{ASSESSMENT OF WATER QUALITY IN SHALLOW WELLS OF COLINAS/RS}

ABSTRACT: Water is very important for biodiversity being considered an essential natural resource for man. Society has recently polluted and degraded this resource so it is no longer possible to consume it in its natural state. However, management, preservation and monitoring of resources have become possible due to technology advancement. For this study, physical, chemical and microbiological analyses of water samples of twelve shallow wells of Colinas/RS were carried out. Analyses of $\mathrm{pH}$, conductivity, turbidity, color, chloride, fluoride, bromate, bromide, nitrate, nitrite, sulfate, most probable number of total coliforms and most probable number of Escherichia coli were performed. Results were compared with the potable water patterns set by Decree \# 2914/2011 of Ministry of Health. It was found that all samples presented microbiological contamination and only five from twelve samples are in accordance with Brazilian regulations regarding physical and chemical parameter. 
The situation becomes potentially severe when such contaminated water is supplying human consumption.

Keywords: Water. Shallow Well. Physical and Chemical Quality. Microbiological analysis.

\section{Referências}

[1] FERREIRA, W. B.; Solução Alternativa de Abastecimento de Água para Consumo Humano em Comunidades Difusas: Monitoramento e Controle de Qualidade da Água. 2008 Dissertação (Mestrado) - Universidade Federal de Campina Grande - UFCG, Centro de Ciências e Tecnologia, Campina Grande, 2008.

[2] BRASIL; Ministério da Saúde. Portaria No 2914, de Dezembro de 2011. Disponível http://bvsms.saude.gov.br/bvs/saudelegis/gm/2011/prt2914_12_12_2011.html. Acesso em 12 jun. 2014.

[3] BRANCO, S. M.; Água: origem, uso e preservação. São Paulo: Moderna, 2001.

[4] SAIDELES, A. P. et al.; Indicativo sobre possíveis problemas de potabilidade em poços no município de Alegrete-RS. Ciência e Natura, Santa Maria, v. 36 n. 3 set - dez. p. 511-518. 2014

[5] MIRLEAN, N. et al.; O Impacto Industrial Na Composição Química Das Águas Subterrâneas Com Enfoque De Consumo Humano (Rio Grande, RS). Química Nova, v. 28, n. 5, p.788-791, 2005.

[6] COSTA, O. L. da; et al.; Análise da qualidade da água de quatro fontes naturais do Vale do Taquari, RS. Revista Destaques Acadêmicos, Lajeado, ano 3, n. 4 , p. 27-33, 2011.

[7] BRASIL. Ministério do Desenvolvimento Urbano e Meio Ambiente. Conselho Nacional do Meio Ambiente (CONAMA); Resolução do no 357, de 17/03/05, Brasília: Brasil.

[8] PALUDO, E.; et. al.; Estudo da qualidade da água em dois municípios na região central, sul do Brasil. Revista Destaques Acadêmicos, Lajeado, ano 4, n. 4, p. 51-57, 2012.

[9] BANCO REGIONAL DE DADOS DO VALE DO TAQUARI; Perfil Socioeconômico do Vale do Taquari. Centro Universitário Univates, Lajeado, set. 2011. Disponível em: <https://www.univates.br/media/bdr/Perfil_VT_Setembro_2011.pdf>. Acesso em: 26 ago. 2014.

[10] PÉRICO, E; CEMIN, G; MOHR, L.R.S. Fisiografia da bacia hidrográfica do rio Forqueta, RS, sul do Brasil. Scientia Plena, vol.8, n. 9, p. 1-9, 2012.

[11] CLESCERI, L. S.; GREENBERG, A. E.; EATON, A. D.; Standard methods for the examination of water and wastewater. 22. ed. Washington (DC): American Public Health Association, 2012.

[12] GOOGLE EARTH; Disponível https://www.google.com.br/maps/place/Colinas+-+RS/@-29.3920302,$51.9321552,13427 \mathrm{~m} /$ data $=! 3 \mathrm{~m} 1$ ! $1 \mathrm{e} 3 ! 4 \mathrm{~m} 5 ! 3 \mathrm{~m} 4 ! 1 \mathrm{~s} 0 \times 951 \mathrm{c} 67 \mathrm{~b} 08913 \mathrm{fa} 9 \mathrm{~d}: 0 x b f 152$ 25218367603!8m2!3d-29.4025182!4d-51.8628399. Acesso em 12 jun. 2014

[13] ROSA, C. C. B. et al.; Qualidade microbiológica de água de poços provenientes de áreas urbanas e rurais de Campos dos Goytacazes (RJ). In: XIII Congresso Brasileiro de Águas Subterrâneas Anais. Cuiabá/MT, 2004.

[14] SILVA, R. de C. A. da; ARAÚJO, T. M. de.; Qualidade da água do manancial subterrâneo em áreas urbanas de Feira de Santana (BA). Ciência \& Saúde Coletiva, Rio de Janeiro, v. 8, n. 4, p. 1.019-1.028, 2003.
[15] SOUZA, K. S. de; PIO, M. C. S.; SANTANA, G. P.; Análise química e bacteriológica da água de irrigação utilizada na Comunidade Agrícola Nova Esperança, Manaus - AM. Rev. Agroambiente, v. 6, n. 3, p. 242-249, 2012.

[16] SALVATORI, R. U.; Determinação de Salmonella Sp. Em embutidos de carne suína. Porto Alegre, 1999.

[17] LOIOLA, H. G. et al.; Influência dos íons cloreto na qualidade das águas subterrâneas de Crateús-CE. In: VII CONGRESSO NORTE NORDESTE DE PESQUISA E INOVAÇÃO, 2012. Anais. Palmas: SETEC, 2012.

[18] LIBÂNIO, M.; Fundamentos de qualidade e tratamento de água. Campinas, SP: Editora Átomo. 2005

[19] FREITAS, S. S.; Eutrofização no Reservatório Marcela em Itabaiana - SE, e suas implicações ambientais. Universidade Federal de Sergipe, 50p. Monografia Especialização em Gestão de Recursos Hídricos e Meio Ambiente, 2001.

[20] ALMEIDA, M. A. B.; SCHWARZBOLD, A. Avaliação Sazonal da Qualidade das Águas do Arroio da Cria Montenegro, RS com Aplicação de um Índice de Qualidade de Água (IQA). RBRH - Revista Brasileira de Recursos Hídricos, v. 8, n.1, 2003, pp. 81-97.

[21] AZEVEDO, R. P. de; Uso de água subterrânea em sistema de abastecimento público de comunidades na várzea da Amazônia central. Acta Amaz. Manaus, v. 36, n. 3, 2006.

[22] AMORIM, J. R. A. de; CRUZ, M. A. S.; RESENDE, R. S.; Qualidade da água subterrânea para irrigação na bacia hidrográfica do Rio Piauí, em Sergipe. Rev. Bras. Eng. Agríc. Ambient., Campina Grande, v. 14, n. 8, 2010. 